\section{How safe is paracetamol?}

\author{
Kristina Star, ${ }^{1}$ Imti Choonara ${ }^{2}$
}

Paracetamol is the most widely used medicine in children, in hospital and in the community. In most countries it is available over the counter and as a prescribed medicine. It is used as an analgesic and an antipyretic. Pain has historically been undertreated in children, especially in preverbal children. In contrast, fever is overtreated, especially in high-income countries. Concerns have been raised regarding the safety of paracetamol in relation to the development of liver toxicity and possible long-term effects in the development of asthma.

Exposure to paracetamol in pregnancy or infancy has been linked with an increased risk of developing asthma. The meta-analysis by Cheelo et $a l^{1}$ however suggests that this is likely to be due to the effect of respiratory infections, rather than the paracetamol itself. The OR of developing asthma after exposure to paracetamol in infancy, after adjusting for respiratory infections was only 1.06 . This suggests that the effect of paracetamol is likely to be minimal. We do however, need to be aware that every medicine has side effects and that medicines should only be given when appropriate.

There have been isolated case reports of infants and preschool children developing liver toxicity following therapeutic doses of paracetamol. We know that young children are less likely to develop acute liver failure than adolescents following an overdose of paracetamol. This is thought to be due to the altered drug metabolism in young children, notably enhanced sulfation and increased glutathione production. We also know from numerous pharmacovigilance studies that deaths from paracetamol in preschool children are extremely rare.

Rajanayagam et al have highlighted the high number of children that developed acute liver failure following medication errors with paracetamol. ${ }^{2}$ As paracetamol is the most widely used medicine in young children and is also available in so many

\footnotetext{
${ }^{1}$ Uppsala Monitoring Centre, WHO Collaborating Centre for International Drug Monitoring, Uppsala, Sweden; ${ }^{2}$ Academic Division of Child Health, University of Nottingham, Derbyshire Children's Hospital, Derby, UK

Correspondence to Professor Imti Choonara,

Emeritus Professor in Child Health, Academic Unit of Child Health, The Medical School, University of Nottingham, Derbyshire Children's Hospital, Uttoxeter Road, Derby DE22 3DT, UK;

imti.choonara@nottingham.ac.uk
}

different formulations, it is not surprising that medication errors occur. What is of concern, however, is the significant number of young children who developed acute liver failure in Australasia following medication errors with paracetamol. While we are learning more about medication errors by health professionals, in hospital and the community, very little is known about medication errors by parents of young children.

Because the study by Rajanayagam et al was a retrospective study, we do not have information as to why the parents committed the medication errors. Doctors will rarely take a full history of medicines that includes over-the-counter medicines and exact dose, frequency of administration and formulation. Additionally, we do not know how extensively non-accidental injury was considered. Parents who have deliberately given their children medicine are unlikely to give this information in the history.

VigiBase is WHO's database of reports of suspected adverse drug reactions submitted by over 100 national pharmacovigilance centres to the Uppsala Monitoring Centre. ${ }^{3}$ The information comes from a variety of sources, and the likelihood that the suspected adverse reaction is drug-related is not the same in all cases. A review of 200 reports on VigiBase of suspected fatal adverse drug reactions to paracetamol in children under the age of 5 years, found that $30 \%$ were reported with medication errors, such as accidental overdose by the parent or health professional, accidental ingestion by the child and incorrect drug administered. Half of these medication error reports were recorded with hepatotoxicity. For the 140 reports without explicit records of medication errors, paracetamol was commonly recorded as a suspected drug with other drugs, that is, paracetamol may not have been the drug responsible for the adverse drug reaction. Unfortunately, many reports did not contain either the weight of the child or the dose of paracetamol, and one could not ascertain whether the dose was appropriate or not. Among the non-medication error paracetamol reports, there were 28 cases of hepatotoxicity. The reported dose was within dosing recommendations in only four of these 28 cases.

Worldwide, over 90 children have died from substandard paracetamol that was contaminated with diethylene glycol in two separate incidents in Haiti and India. ${ }^{4}$ A similar number of children died from the administration of counterfeit (falsified) paracetamol in Bangladesh and Nigeria. Substandard and falsified medicines are a major issue in low and lower middle income countries with an estimated prevalence of $28.5 \% .^{5}$ They are also a problem in high income countries. They are however an increasing problem and one that is rarely considered. It is extremely unlikely that if either a substandard or falsified formulation of paracetamol entered into the market in a high income country, that doctors would have specified the formulation in a history taken in a child presenting with acute liver failure.

Health professionals have a responsibility to try minimising medication errors by parents by ensuring that parents are fully informed about any medication they intend to give to a child. Paracetamol is a very safe compound. This can be further improved by instructing parents and caregivers appropriately and ensuring safe formulations.

\section{Competing interests None}

Provenance and peer review Commissioned; internally peer reviewed.

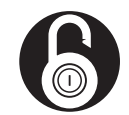

\section{OPEN ACCESS}

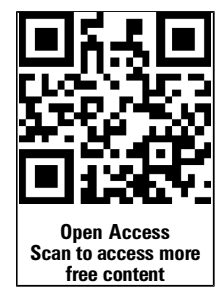

Open Access This is an Open Access article distributed in accordance with the Creative Commons Attribution Non Commercial (CC BY-NC 4.0) license, which permits others to distribute, remix, adapt, build upon this work non-commercially, and license their derivative works on different terms, provided the original work is properly cited and the use is noncommercial. See: http://creativecommons.org/licenses/ by-nc/4.0/

To cite Star K, Choonara I. Arch Dis Child 2015;100:73-74.

Received 2 October 2014

Revised 25 October 2014

Accepted 27 October 2014

\section{Linked}

http://dx.doi.org/10.1136/archdischild-2013-304902

Arch Dis Child 2015;100:73-74.

doi:10.1136/archdischild-2014-307431

\section{REFERENCES}

1 Cheelo M, Lodge CJ, Dharmage SC, et al. Paracetamol exposure in pregnancy and early childhood and 


\section{Editorial}

development of childhood asthma: a meta-analysis. Arch Dis Child 2015;100:81-89.

2 Rajanayagam J, Bishop J, Lewindon P, et al.

Paracetamol-associated acute liver failure in Australian and New Zealand children: high rate of medication errors. Arch Dis Child 2015;100:77-80
3 Lindquist M. Vigibase, the WHO Global ICSR database system: basic facts. Drug Info J 2008;42: 409-19.

4 Alkahtani S, Sammons H, Choonara I. Epidemics of acute renal failure in children (diethylene glycol toxicity). Arch Dis Child 2010;95:1062-4.
5 Almuzaini T, Choonara I, Sammons H. Substandard and counterfeit medicines: a systematic review of the literature. BMJ Open 2013;3:e002923. 